\title{
SPEAKING UP, SPEAKING OUT
}

Lived Experiences of Non-Tenure-Track

Faculty in Writing Studies

EDITED BY

JESSICA EDWARDS,

MEG MCGUIRE,

AND RACHEL SANCHEZ

UTAH STATE UNIVERSITY PRESS

Logan

Copyrighted material

Not for distribution 
(ㄷ) 2021 by University Press of Colorado

Published by Utah State University Press

An imprint of University Press of Colorado

245 Century Circle, Suite 202

Louisville, Colorado 80027

All rights reserved

Manufactured in the United States of America

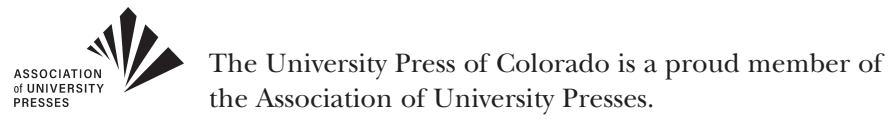

The University Press of Colorado is a cooperative publishing enterprise supported, in part, by Adams State University, Colorado State University, Fort Lewis College, Metropolitan State University of Denver, Regis University, University of Colorado, University of Northern Colorado, University of Wyoming, Utah State University, and Western Colorado University.

$\infty$ This paper meets the requirements of the ANSI/NISO Z39.48-1992 (Permanence of Paper).

ISBN: 978-1-64642-074-2 (paperback)

ISBN: 978-1-64642-075-9 (ebook)

https://doi.org/10.7330/9781646420759

Library of Congress Cataloging-in-Publication Data

Names: Edwards, Jessica, 1984- editor. I McGuire, Meg (Professor), editor. I Sanchez, Rachel, editor.

Title: Speaking up, speaking out : lived experiences of non-tenure track faculty in writing studies / edited by Jessica Edwards, Meg McGuire, Rachel Sanchez.

Description: Logan : Utah State University Press, [2021] I Includes bibliographical references and index.

Identifiers: LCCN 2020049979 (print) I LCCN 2020049980 (ebook) I ISBN

9781646420742 (paperback) I ISBN 9781646420759 (ebook)

Subjects: LCSH: College teachers-United States. I Writing centers-United States. I Academic writing — Study and teaching (Higher)—Social aspects—United States. I Universities and colleges-United States-Faculty.

Classification: LCC LB1778.2 .S64 2021 (print) I LCC LB1778.2 (ebook) I DDC $378.1 / 20973-\mathrm{dc} 23$

LC record available at https://lccn.loc.gov/2020049979

LC ebook record available at https://lccn.loc.gov/2020049980

Cover illustration @ Rinat Khairitdinov/Shutterstock

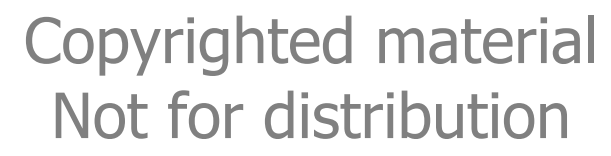




\section{CONTENTS}

Acknowledgements vii

Introduction: Negotiating Non-Tenure-Track Identities

Jessica Edwards, Meg McGuire, and Rachel Sanchez 3

\section{PART I: DEFINITIONS}

1. Practice Doesn't Always Make Permanent: Directing a Writing Center as a Professor of Practice

Rachel Azima $\quad 15$

2. How Student Affairs Praxis Can Aid the Nexus of Emotional Labor for NTTF

Peter Brooks 28

3. Contingent Faculty in the Gig Economy: A Conversation, Comparison, and Call

Erica M. Stone and Sarah E. Austin 42

4. "What Are You?": Rethinking Frames for Contingent Writing Center Work

Liliana M. Naydan 59

\section{PART II: CRITICAL PERSPECTIVES}

5. Having It All: The Costs and Opportunities of Non-Tenure-Track Faculty's Institutional Progress

Lacey Wootton 73

6. Ghosts in the Building: Investigating Contingent-faculty Experiences Brendan Hawkins and Julie Karaus 90

\section{Copyrighted material Not for distribution}




\section{PART III: LIVED EXPERIENCES}

7. An Inconvenient Truth: Labels and Limits in Writing Center Directorship

Megan Boeshart Burelle and Elizabeth J. Vincelette 107

8. A Tale of Two Pities: An Inside Look at a Dual Non-Tenure-Track Household

Jessica Cory and John McHone 119

9. The Sound of Silence: Negotiating Non-Tenure-Track Invisibility within the Institution

Angie McKinnon Carter, Christopher Lee, and Linda Shelton

10. Disunity in a Writing Community: A Post-PhD Memoir of Professional Transitions

Liz Gumm 145

11. Collective Bargaining, Heterogeneity, and Non-Tenure-Track Writing Faculty

Denise Comer 158

12. Off Track and Sidetracked

Seth Myers 177

PART IV: NEXT STEPS

13. Collaboration as Antidote to NTTF Pressures

Nathalie Joseph and Norah Ashe-McNalley 193

14. Collaboration Is Critical, but Further Considerations Are Needed for NTTF

Heather Jordan 207

15. Faculty Community Building: Portfolio-Assessment Groups as Teaching Circles

Dauvan Mulally

About the Authors

Index 237

\section{Copyrighted material Not for distribution}




\section{NTROD UCTION \\ Negotiating Non-Tenure-Track Identities}

Jessica Edwards, Meg McGuire, and Rachel Sanchez

This collection began with three non-tenure-track faculty members (NTTF) struggling to understand our professional identities in the context of a tenure system. We were faculty without an understanding of our place in that system and without clear connections to the community of NTTF who comprise our cohort, perhaps in part because the language used to identify us is so inconsistent.

Contingent faculty. Adjuncts. Non-tenure-track faculty. Instructors. Lecturers. Clinical professors. Term faculty. Part-time faculty. Our collective professional identities are wrapped up in language that is not only not controlled by us but is also the language of our commerce-how we are packaged as commodities-because not only are the labels inconsistent, but the work we are asked to do under each label is inconsistent, as you will read in this collection. Some of us do administrative work, and some of us do not. Some of us are in a position to be promoted, and some of us are not; some of us are not interested in promotion. Some of us cobble full-time positions out of many part-time positions, and some of us do not. These staggering inconsistencies make it difficult for our tenured or tenure-track (TT) counterparts to understand the work we do, inside or outside the classroom, and the lengths we must often go in order to remain committed to our students and colleagues.

The rhetorical power of these labels is in defining our worth to our peers and administrators, in framing the scholarship we produce in the name of our institutions, and in defining our worth to our institutions themselves. But we know NTTF are consistently defined by what we are not in all the above contexts. Often, such defining is incorporated into our titles, yet there are other ways the institution identifies NTTF by what we are lacking. We do not only lack tenured status, we lack focus. We do not only lack voting rights, we lack institutional memory. We do not only lack stability in our employment contracts, we lack power to communicate our ideas and woes in proper institutional channels. 
For instance, a contingent-faculty member at one college labeled as an instructor might have the same contract as someone who is labeled an assistant professor at another institution.

This slipperiness of language on a national scale presents a lack of consistency that must be made visual, shared, and challenged in order to curtail the histories that have relegated NTTF to the boundaries. While non-tenure-track faculty (NTTF) is imperfect in its deficit approach to labeling, we chose this term for the collection because it most closely encompasses all our titles. As we work to speak up and speak out, providing a space to communicate a few of the many stories that exist, sharing details about our professional and personal lives that give fuller insight into the experiences of NTTF, we hope to open a needed dialogue about how to value the very people who take on such physical, rhetorical, and emotional work. In our discipline's critical work of ensuring the future of writing studies, we must understand who teaches so many of these courses.

The linguists and philosophers George Lakoff and Mark Johnson (1980) use much of their text Metaphors We Live By to argue the power conceptual metaphor-and rhetoric-has on our basic understanding of the world around us, including the roles we inhabit, the ways we situate our identities within a larger world. Conceptual metaphors, they tell us, play a role in "the construction of social and political reality" (159), and the political reality of NTTF has and will always be tied to the language used to identify and talk about that body of workers. Because we exist in a tenure system, the labels tied to NTTF replicate that system without replicating any of the associated power.

If we believe in Antonio Gramsci's (2005) idea that sedimentations from one "historic bloc" are often found in another, or Michael Omi and Howard Winant's (1994) claim about rearticulation and how systemic structures are often revamped in different historic blocs to feed hegemony, it is easy to understand the rhetorical vibrato of NTTF conversations. Although this landscape is largely focused on quality teaching and access to teaching opportunities and service for NTTF, there are many mountains to climb, as attention to inequality and struggles for legitimacy cannot be ignored. Adjunct professors and non-tenured folk all over the country are faced with challenges, from material conditions to lack of literal time to just get work done. Faculty of color experience problems at the intersections of race, gender, identity, and even income within and outside NTTF positions. These problems cause disenfranchised people to experience life differently from their white counterparts. Although there are very few data about NTTF demographics

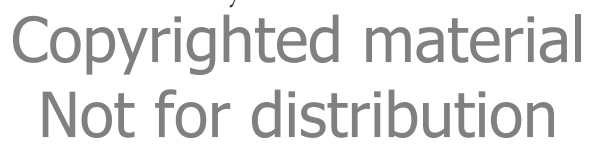


related to race, Kimberlé Crenshaw's (2016) work "The Urgency of Intersectionality" underscores the importance of understanding how power works and how disenfranchised people are often hit with multiple types of discrimination at once. Crenshaw notes she "began to use the term 'intersectionality' to deal with the fact that many of our social justice problems like racism and sexism are often overlapping, creating multiple levels of social injustice."

We write of our non-tenure-track faculty in this collection, of our adjunct family, of ourselves, yet we cannot write about ourselves in a singular way. We want to write about ourselves, yet we do not control the language that defines ourselves. We want to reject the homogeneity of an NTTF identity and engage with the tools to establish the myriad, complex identities that comprise more than half the teaching force at most institutions in this country. Throughout this introduction, we editors share our own brief stories about being NTTF and, like the authors who follow, we strive to engage the differences in our experiences, personal lives, and outlook on teaching and administration to paint a clearer picture of NTTF life during another sea change for higher education.

\section{JESSICA}

The work of developing a professional identity, of discovering exactly what it means to not be on a TT track, was a long road of soul searching for me as I worked to, as Audre Lorde famously said, "define myself for myself." When I teach writing classes, I often use the first two weeks to encourage students to think about their own identity. I am of the mind that much of what we do and what we write is tied to a set of beliefs we hold; I also think if we can understand who we are and what shapes us, we are in a better position to navigate in meaningful ways. My approaches to teaching have certainly helped me better understand my professional identity, as I now think of myself as a pedagogical researcher dedicated to the scholarship of teaching; in my first teaching job, however, I was challenged to consider my professional identity in ways that required me to dig into the rhetorical nature of job labels and how they affect self-awareness. As Denise Comer notes in this collection, "The Conference on College Composition and Communication offers a deliberately expansive definition of NTTF: 'all faculty who are not protected by tenure.' Still, the range of heterogeneity emphasizes the complex and varied systems that impact NTT labor and may even contribute to the inequities themselves" (chapter 11). Because of possibilities of what an NTTF might look like, NTFF may need to discover their own

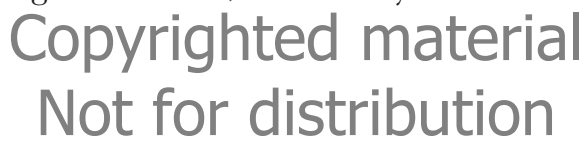


professional identities. Throughout my journey, not only did I have to take time to consider the realities of my position, I had to think through what was possible in the role to help me define myself and my work.

Immediately, I understood that high-impact practices would not be possible for me to sustain. Heather Jordan notes in her chapter "Collaboration Is Critical, but Further Considerations Are Needed for NTTF," NTTF are often expected to engage in "high-impact practices" that "require significant time and energy contributions on the part of the faculty member" (chapter 14). These high-impact practices vary but can combine consistent excellence in research, teaching, service, mentoring, volunteering, personal life, invisible labor, and more. The reality is that consistent excellence and engagement in high-impact practices is not healthy for any faculty member, especially NTTF. So, for me, determining what was most important to me mattered greatly to my ability to develop an identity I would be able to share with folk in any setting so as to not sacrifice my professional integrity, my health, or my personal life. I had to structure time each day to write, to think, which led me to consider more clearly my professional practices. Focusing on the scholarship of teaching helped me align myself as a professional. Seeing myself as a pedagogical researcher, dedicated to the life of the mind, helped me find footing. Understanding my craft as not only an important part of the larger fabric of the institution but also as an extension of me helped me feel more grounded. Having a strong support system of family, friends, and colleagues who continually remind me of the significance of my contributions mattered. Finding avenues to assert my voice proved valuable. I had to, in many ways, create these conditions using what was available to me, and that made all the difference.

$$
* * *
$$

The potential fracture of identity that comes with taking on an NTTF position and the need to put yourself together deserves more attention. Part of the problem is that there are few places to share that not only validate NTTF experiences but also allow for the experiences to serve as tools for thoughtful engagement. We created this space to amplify those stories and identities so more NTTF can be seen, heard, and understood. In so doing, we create another avenue where NTTF identities are embraced and celebrated.

\section{MEG}

From the outside, my NTTF position does not appear to be that different from those that are tenure track. I have full voting rights in faculty

\section{Copyrighted material Not for distribution}


meetings; I serve on important and worthwhile committees; overall, I am meant to be a valued member of my institutional community. I get the traditional, more seemingly prestigious title of associate professor. There are no of qualifiers like of practice or of teaching in my title. I had the opportunity to be promoted from assistant to associate professor, and I hope to someday be promoted to full. My membership in my institutional community may be viewed and believed by many to be inclusive, but like everyone in this collection, some areas in which the institution strives for inclusiveness actually reinforce my exclusion.

This mixed message of inclusiveness was most apparent in my recent promotion process. The process was exactly the same as if I were applying for tenure. I compiled a full dossier with statements that outlined my teaching and service. My dossier was sent out to external reviewers, selected from some of the most important people in my field. A number of students gave statements on my teaching. The process was challenging, especially in trying to convey how my workload and the work I do as NTTF matters to the university I work for. It is a different argument than one made by TT faculty, yet the dossier looks similar. The only difference is that I do not have a research section. But I had done scholarship as NTTF, and that scholarship was also included, not in a separate scholarship section but as part of my teaching statement. NTTF are not expected to produce articles or books, yet we are encouraged to do so, so the articles and book chapters acted as a testament to the work I put into my teaching and how the work I do gives me room to strive to be better as a teacher by bringing this knowledge into the classroom. But publishing is not, again, on paper, important to our performance review as teachers. And yet, reading between the lines, if NTTF want to be promoted, we are encouraged to produce articles, or books. In fact, in every letter I received in support of my promotion case, my research was discussed as just that. Almost all comments regarding my scholarship made some point about how impressive it was that I had had such a full teaching load and was still producing scholarship. Not one comment was made about how it strengthened my teaching or discussed what kind of scholarship it was.

What I took from this experience is that NTTF, in order to further succeed at the university, especially in terms of a dossier, must look like TT faculty, even if we are not always valued as such. I am fortunate I am able to include my scholarship, unlike NTTF at some universities that advocate for no scholarship at all, as Angie McKinnon Carter, Christopher Lee, and Linda Shelton discuss in their chapter "The Sound of Silence: Negotiating Non-Tenure-Track Invisibility within the

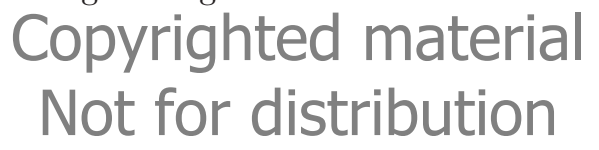


Institution" about their own promotion experiences. But the review process for contingent faculty is designed for tenure-track faculty, assessed by tenure-track faculty, and decided upon by tenure-track faculty. One could argue this process is one way to make NTTF valued and included. NTTF go through a vigorous process that assesses their work and merits achieved in a certain time frame because they are just as important as the work and merits of TT faculty. Many of my colleagues involved in this collection and I argue that this process exists because, as many NTTF faculty working in writing and English departments nationally know, universities don't know how to account for the work NTTF do. They know what they want NTTF to do; they want them to teach classes. Even the MLA, in its Statement on the Use of PartTime and Full-Time Adjunct Faculty Members, states, "Adjunct faculty members should be hired, reviewed, and given teaching assignments according to processes comparable to those established for the tenured or tenure-track faculty members" (2020). This advocacy, though made in good faith, does little to create equity and inclusion. Adjuncts are supplemental to the perceived permanency of tenure, a truth tied more to language than to practice, as the ranks of NTTF grow to not only equal those of their tenured counterparts but to surpass them significantly. Adjuncts are supplemental to the idea of tenure but are not supplemental to undergraduate education; their labor is where undergraduate education lives.

$$
* * *
$$

Because NTTF labor can be seen as a threat to the traditional tenure system, as evidenced by such texts as the WPA listserv, where frequent arguments are made about the value and impact of NTTF, the sense of isolation and exclusion felt by NTTF grows even as university administrators create programs and paths that seek to aid in NTTF development. Strange that such labor is viewed as a threat at all when its very existence is contingent, is paid a fraction of what TT labor is paid, and has never contained a back-door or secret, easier path to tenure. What is less strange is that educators would take on an NTT appointment at all, given the vulnerabilities related not only to the position but also to the profession. We are professionals who are as committed to our students, scholarship, and institutions as our TT counterparts, but we are also people with responsibilities that demand our attention, demand we take positions steeped in vulnerability in order to survive the economic and personal realities of being postsecondary writing instructors with significant student debt in a world that increasingly devalues liberal arts education.

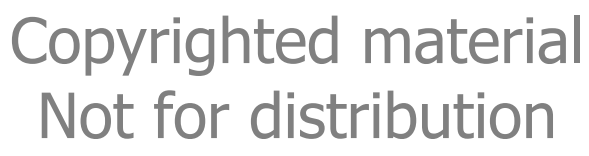




\section{RACHEL}

I was a month into living in a friend's basement when I received my first contract offer. Knowing there weren't jobs in my hometown for recently minted MAs of English literature, I had developed enough fear that, when I received the email from my former department chair asking if I was looking for a teaching job, I didn't hesitate. The job was part time. I couldn't afford moving back to the college town I had only recently vacated, so I had to borrow from a graduate school friend, also a new MA, to cover my moving expenses. The narrative of MA graduates being what it is, and the preparation of graduate students for professions outside academia being what it is, I believed this offer was the best I should expect.

A bridge appointment. That's what our profession calls it, yet the trouble with that label is that it supposes the employer is invested in assisting the employee in crossing that bridge from apprentice to expert. Those first couple of years, I worked under a department chair who did not know who I was. I didn't receive annual reviews. I didn't know I could or should be attending department meetings and had even been encouraged not to go. The work was being sold to me, in most respects, as an extension of graduate school without required seminars. My closest ally and the person responsible for mentoring me was another MA graduate with one year of teaching experience beyond my own, another bridge appointee on her way to a PhD program. TT faculty, whom I saw as treasured and critical mentors, asked about upcoming $\mathrm{PhD}$ plans, and regardless of intention, this question implied a limitation to the position that had not occurred to me when I accepted it. Looking back, I understand; a bridge appointment is only that if I am walking across the bridge from the place I was-a space untenable, of unreliable contracts and fewer professional benefits- to the promised land: tenure. And if not tenure, then to the space we rarely discuss in graduate school: the real world. This untenable space is difficult to live within, and it can be difficult to know where you are or where you need to go, especially as a new instructor two months outside her MA, only six years outside high school.

But ours is a position of contradictions, and it is also worth noting that during this half-time employment, I was benefit eligible. My life filled with complications, yet I never worried that my job was in danger as a result. Quickly after I took on significant family responsibilities, my contract stretched to full time, thanks in large part to a new department chair. Later, I brought a toddler with me to class, and nobody cared. A canceled class was not strike one in a three-strike system. My department did not close new teaching opportunities to me after a disastrous attempt at teaching my first upper-division class but instead provided

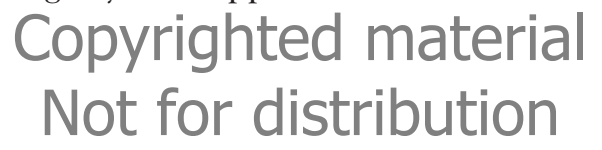


me additional opportunities-I taught new upper-division courses, then I taught online, then I taught courses for multilingual students, then I taught courses for basic writers. For NTTF, life exists within the space of these contradictions, as Seth Myers details beautifully in "Off Track and Sidetracked," in this collection, and what we carry with us in that space is our commitment to the work. Our identities as professors are not contingent, a truth that no doubt contributes to our (dys)functional relationship to our positions. We love the work we do, and we are so lucky to be employed by institutions even though they find us too lacking in one way or another to be seen as permanent; we are so lucky to be housed in departments with such significant service-course responsibilities that what we lack is necessarily overlooked.

It's a phrase I've heard repeatedly as NTTF, a refrain in our nonofficial theme song. We're so lucky; it could be so much worse. We could have semester or quarter-long contracts. We're so lucky. We could make so little we must seek employment from two or more universities. It could be so much worse. We could have classes taken away from us a week before starting class. We could be ineligible for benefits. We could have even less than we have now, we're soooooooo lucky.

$$
* * *
$$

The contradiction of our employment-our existence-is tough to understand outside the vantage point NTTF call home. It is a space of averages, tallying what we have so we might leverage it against what we do not have, what we're told might never be ours. Consequently, this collection challenges the institution and all who participate within it, asking for clear ways contingent faculty fit into the system. It challenges tenure-track counterparts who often want to support NTTF but lack an understanding of how contingent faculty are seen and valued. Finally, this collection challenges the collective identities within the contingentfaculty cohort across the nation. We have all chosen our careers for a variety of reasons and bring with us our own background experiences. So the authors of these fifteen chapters have been brave to share their stories by speaking up and helping define what the nontenure track is and by beginning to offer suggestions for ways we can come together as a community and how we might better fit within our departments and institutions.

\section{REFERENCES}

Crenshaw, Kimberlé. 2016. "The Urgency of Intersectionality." TED video, 18:41. https:// www.ted.com/talks/kimberle_crenshaw_the_urgency_of_intersectionality?language=en.

\section{Copyrighted material Not for distribution}


Gramsci, Antonio. 2005. Selections from the Prison Notebooks, edited by Quintin Hoare and Geoffrey Nowell Smith. New York: International.

Lakoff, George, and Mark Johnson. 1980. Metaphors We Live By. Chicago: University of Chicago Press.

Modern Language Association. 2020. "Statement on the Use ofPart-TimeandFull-TimeAdjunctFaculty Members." https://www.mla.org/Resources/Research/Surveys-Reports-and-Other -Documents/Staffing-Salaries-and-Other-Professional-Issues/MLA-Statement-on-the -Use-of-Part-Time-and-Full-Time-Adjunct-Faculty-Members.

Omi, Michael, and Howard Winant. 1994. Racial Formation in the United States: From the 1960s to the 1990s. New York: Routledge.

\section{Copyrighted material Not for distribution}

